\title{
Problemas y desafíos en torno al anticipo del impuesto a la renta
}

\author{
Problems and Challenges Regarding the Advance Payment of \\ Income Tax
}

Problemas e desafios em torno do pagamento antecipado do imposto de renda

\author{
Stephany Olarte Benavides \\ Universidad Andina Simón Bolívar (Sede Ecuador) \\ stephyolarte@gmail.com
}

DOI: https://doi.org/10.32719/25506641.2019.5.3

Fecha de presentación: 19 de diciembre de 2018 • Fecha de aceptación: 17 de abril de 2019 Artículo de investigación

Licencia Creative Commons

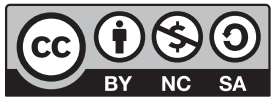




\section{Resumen}

Se analizan los problemas jurídicos del sistema de anticipación en el pago del impuesto a la renta; el objetivo es evidenciar los problemas que plantea su regulación, así como la implicación como un impuesto encubierto, que distorsiona las bases de la progresividad, por estar categorizando a contribuyentes diferentes en términos desiguales. La metodología del estudio es cualitativa, documental bibliográfico. A través de un análisis de las teorías del tributo y de los principios que guían su aplicación se desentraña el sistema de ingresos anticipados en su contenido sustancial y se presentan posibles soluciones.

Palabras clave: Anticipo, impuesto a la renta, técnica impositiva, doble imposición interna Ecuador.

JEL: K34 Derecho fiscal; H24 Impuesto y subvenciones de la renta personal y otras rentas no empresariales.

\section{Abstract}

This paper analyses the legal issues of the anticipation system regarding to the payment of income tax; aims to highlight the problems posed by the regulation of the income tax advance and its implication as a hidden tax, that distorts the bases of progressivity, over categorizing different taxpayers in unequal terms with tax treatments not responding to fair contributions. The methodology is qualitative, bibliographic documentary nature. By means of an exhaustive analysis of the tribute theories and the principles guiding its application, the anticipated income system is revealed in its substantial content, and possible solutions are presented.

Keywords: Advance payment, income tax, tax technique, internal double taxation Ecuador. JEL: K34 Tax Law; H24 tax and subsidies on personal income and other non-business income.

\section{Resumo}

Este artigo analisa os problemas jurídicos do sistema de antecipação no pagamento do imposto de renda; O objetivo desta pesquisa é destacar os problemas colocados pela regulamentação do imposto de renda e sua implicação como um imposto oculto, onde se pretende explicar que a técnica tributária distorce as bases da progressividade, pois está categorizando diferentes contribuintes em termos desiguais. A metodologia do estudo é qualitativa, de natureza documental bibliográfica. Através de uma análise exaustiva das teorias do tributo e dos princípios que guiam sua aplicação, o sistema de renda antecipada é desvendado em seu conteúdo substancial e possíveis soluções são apresentadas como ferramentas.

Palavras-chave: Adiantamento, imposto de renda, técnica tributária, dupla tributação interna no Equador.

JEL: K34 Direito tributário; H24 imposto e subsídios sobre renda pessoal e outros rendimentos não comerciais. 


\section{Introducción}

E

1 anticipo, como una figura técnica de naturaleza impositiva, adaptada en Ecuador con una variedad en sus transmutaciones o mímesis, ha tenido en algunos escenarios pocas posibilidades de éxito. Desde ahí parte el cuestionamiento de si este instrumento responde a las bases de su creación que fueron el control de la elusión y la evasión, recaudación y gestión, o si su naturaleza múltiple responde a un impuesto encubierto.

En ese sentido -se ha pasado por alto discutir sobre el componente esencial que inquieta la regulación del anticipo del impuesto- se habla de la imposición de elementos que no están acordes al objeto materia del impuesto. La lógica de cada punto en la problemática tiene por fin demostrar que la raíz de todo esto es que se toma en cuenta en el anticipo a un objeto imponible diferente.

Los elementos que sirven como cálculo para la base del anticipo, no son los mismos considerados en la categoría de rendimientos del impuesto. El alcance que ha tenido esta defectuosa regulación es cubrir con un mecanismo de pago a otro impuesto totalmente distinto. A ello debe sumarse que la desagregación de los elementos de la base de cálculo del anticipo permite evidenciar el fenómeno de doble imposición interna, en el que tanto tributos locales como el anticipo gravan a un mismo sujeto, durante un mismo período impositivo y sobre la misma materia imponible. Tal andamiaje de dificultades afecta a varios principios como la igualdad, la capacidad contributiva, la unidad en el régimen, y la seguridad jurídica, garantías que van de la mano con la coordinación de todos los tributos considerados a nivel territorial.

El objetivo de esta investigación es evidenciar los problemas jurídicos que plantea la regulación del anticipo del impuesto a la renta y su implicación como un impuesto encubierto; se pretende explicar que la técnica impositiva distorsiona las bases de la progresividad por estar categorizando a 
contribuyentes diferentes en términos desiguales, con tratamientos impositivos que no responden a justas contribuciones. Para ello, se realizó un análisis documental y una comparación con otras legislaciones y jurisprudencia en el período comprendido entre los años 2015 y 2016.

El documento inicia con el análisis del régimen tributario y la técnica de imposición. Posteriormente se analiza la materia imponible, y se categoriza al anticipo como un impuesto encubierto en el que existe confusión de objetos imponibles. Adicionalmente se analizan los problemas de doble imposición interna y sus relaciones con varios impuestos nacionales. Finalmente, se proponen algunas vías de solución a la problemática analizada.

\section{La problemática del anticipo}

El régimen tributario, configurado sobre la base de la coordinación de principios ordenadores, precisa que toda disposición normativa que regule la base imponible llegue a cuantificar sus objetos articuladamente con las circunstancias subjetivas que presenta la naturaleza de cada tributo.

En palabras de Jarach $(1999,384)$ : "La base imponible representa uno de los elementos constitutivos del hecho imponible y responde a la necesidad de cuantificar dicho presupuesto de hecho a fin de aplicar sobre esa cantidad el porcentaje o la escala progresiva cuya utilización dará como resultado el importe del impuesto".

Esta línea de análisis corresponde muy bien a la evidencia que persigue un primer acercamiento a la problemática: se debe partir mencionando que la desarticulación entre la base de cálculo del anticipo con la base de imposición de renta se establece por varias vías. En primer lugar, la técnica de imposición presenta un escenario contrapuesto, mientras el anticipo maneja una tarifa única proporcional, el impuesto a la renta presenta una tarifa que varía progresivamente según el caso. En segundo lugar, la materia gravable se encuentra comprendida de forma distinta, por una parte, el impuesto afecta rentas, réditos, ganancias, dividendos y otros similares, y la afectación en el anticipo es sobre activos y patrimonio. 


\section{En relación a la técnica de imposición}

A fin de abordar el primer punto de la problemática de la desarticulación, es necesario partir de la valoración del tipo impositivo que tiene el impuesto a la renta. La Ley de Régimen Tributario Interno (en adelante LORTI) ha establecido una doble posibilidad; por una parte, las personas naturales y sucesiones indivisas no obligadas a llevar contabilidad deberán sujetarse a una tarifa progresiva definida por escalones, en un rango que oscila entre el 0 al 35\% de sus ingresos gravables; la progresividad, según el autor Pérez de Ayala $(1978,59)$, consiste: "en que cuanto mayor sea el valor de la base imponible más alto será el porcentaje que la ley manda aplicar".

Corresponde ahora examinar el tipo impositivo que presenta el contexto normativo del anticipo. Los tipos impositivos son distintos con respecto al del impuesto, por tanto, para un grupo la tarifa es de tipo fijo proporcional y para otros es fija dependiendo de la distinta naturaleza de los objetos que esté afectando.

En esa línea, como bien enseña Pérez de Ayala (1978, 61): "El tipo proporcional es siempre un porcentaje fijo de la base imponible, cualquiera que sea el valor de esta". Hay que agregar que la forma de cálculo de la base del anticipo presenta varias distinciones. Así los parámetros instituidos en el art. 41 de la Ley Orgánica de Régimen Tributario Interno (EC 2004) establecen diversas reglas para efectuar el pago del anticipo:

a) Las personas naturales y sucesiones indivisas no obligadas a llevar contabilidad, las empresas que tengan suscritos o suscriban contratos de exploración y explotación de hidrocarburos [...] Una suma equivalente al 50\% del Impuesto a la Renta determinado en el ejercicio anterior, [...]; b) Las personas naturales y las sucesiones indivisas obligadas a llevar contabilidad y las sociedades: Un valor equivalente a la suma matemática de los siguientes rubros: $-\mathrm{El}[\ldots][0,2 \%]$ del patrimonio total. $-\mathrm{El}[\ldots][0,2 \%]$ del total de costos y gastos deducibles a efecto del Impuesto a la Renta. $-\mathrm{El}[\ldots][0,4 \%]$ del activo total. $-\mathrm{El}$ $[\ldots][0,4 \%]$ del total de ingresos gravables a efecto del Impuesto a la Renta. [...] Instituciones financieras un [3\%] de los ingresos gravables.

De acuerdo con la norma antes aludida, el anticipo se manifiesta como parte accesoria con categoría impositiva, presenta tarifas que repercuten de alguna manera en términos de igualdad y congruencia con en el tipo impositivo que se maneja en el impuesto a la renta. 
Parte de la doctrina que estudia la técnica de los impuestos, como Albiñana García, Schmölders y Benvenuto Griziotti, se ha inclinado por defender que en el impuesto a la renta se debe emplear "la tarifa progresiva en vez de proporcional sobre la renta" (Schmölders 1962, 42). Adicionalmente, las capacidades adquisitivas son distintas, y los porcentajes de cálculo del anticipo afectan gravemente el principio de igualdad. Para Schmölders $(1962,45)$ :

La igualdad significa también «que el impuesto guarde en lo posible relación con la capacidad económica, que va creciendo en mayor proporción de lo que aumenta la renta absoluta [o el patrimonio], lo que requeriría que se gravara más las rentas de propiedad que las de trabajo, mediante impuestos complementarios sobre el patrimonio y el capital.

De lo expuesto, es preciso hacer énfasis que las atribuciones legales para el cálculo del anticipo deben ser congruentes con el impuesto a la renta.

\section{La materia imponible}

Propiamente la vía de desarticulación que nos referíamos al principio de este apartado tiene que ver con la materia gravable y la forma errónea que se encuentra instituida en el cálculo del anticipo. Este elemento constitutivo del impuesto no debe ser estructurado arbitrariamente, sino que debe aplicarse en razón de los principios y proporciones de la técnica adecuada del tributo.

La riqueza que se afectará por el impuesto deberá ser la misma considerada para efectuar el cálculo de su anticipación en el pago, sea actual o futura la posesión que tenga el sujeto destinatario del impuesto. En ese sentido, Pérez de Ayala $(1978,41)$, al analizar las características de la materia imponible, explica que:

Si el impuesto se establece sobre unos determinados recursos con el fin de gravar por parte de ellos a su actual o futuro beneficiario [...] está claro que la única base lógica para determinar en función de ella cuál ha de ser la cuantía correcta del gravamen, estará constituida por el valor de los propios recursos sometidos a este último.

La realidad concreta constituida en materia de imposición, a efecto del impuesto a la renta, afectará únicamente a la manifestación de renta, esta estimación objetiva es delimitada en nuestra ley como de carácter global, es 
decir "que somete a un solo y mismo impuesto a todas las materias imponibles que se pueden reducir o pertenecen a la misma categoría conceptual" (Pérez de Ayala 1978, 42 énfasis añadido).

Sucede que los preceptos de la normativa que se analizan consideran, en el caso de personas naturales, sucesiones indivisas no obligadas a llevar contabilidad, sociedades que tienen contratos de hidrocarburos e instituciones financieras, y que la afectación tanto en el impuesto como en el anticipo es únicamente sobre ingresos gravables. En este grupo de contribuyentes la base del anticipo obedece acertadamente la técnica jurídica empleada por la del impuesto en relación al objeto gravable.

Por otro lado, considerando como fundamento principal la problemática descrita en relación a la base del anticipo, la LORTI tiene un método diferente para el régimen cuantitativo del impuesto. En ese contexto, la ley ecuatoriana fiscal ha establecido que, en el caso de personas naturales, sucesiones indivisas obligadas a llevar contabilidad y sociedades en general, el impuesto afecta varias categorías de rendimientos, pero en el anticipo esa afectación recae sobre el patrimonio total, el total costos y gastos deducibles, el activo total y el total de ingresos gravables.

Pero el caso es que toda certeza jurídica que debe presentar la ley se abate por la configuración de la base imponible del anticipo. De aquí que ha resaltado Calvo Ortega $(2006,187)$ las consecuencias relativas de la base imponible, al decir:

Tiene que recoger con la máxima fidelidad la capacidad económica [...] tiene que ser neutral y no puede aumentar ni reducir la capacidad económica [...] La exigencia de fidelidad a que nos referimos condiciona la elección de técnicas y datos para determinar la base con un margen muy escaso de opciones. Así, un impuesto sobre la renta en su configuración actual atenderá a la diferencia entre ingresos y gastos vinculados a aquellos con un grado de necesidad suficiente.

Es decir, lo que representa la determinación del anticipo lesiona también el principio de justicia tributaria, por tomar en cuenta técnicas y objetos imponibles distintos al de la renta, es decir, al patrimonio y los activos, a causa de que estos no generarán renta, sino que necesitan de un período para generarla y para que opere un impuesto sobre ellos, y por tanto sea exigible legalmente. 
Schomölders $(1962,44)$ destaca que:

La verdadera fuente del impuesto ha de ser la renta y no el patrimonio. La desgravación fiscal del patrimonio y del capital, la repulsa cualquier impuesto que grave efectivamente el capital o el patrimonio es [...] un principio general e importantísimo de la moderna teoría del impuesto y una consecuencia de la función del capital desempeña en la economía, particularmente en la producción.

Esta estimación, en la base del impuesto y la consideración de sus magnitudes, debería aplicarse estrictamente igual a la base del anticipo. Sin embargo, como se ha mencionado, el anticipo considera un régimen híbrido al tener en cuenta la base vía renta, vía patrimonial, activos, costos y gastos; este último no es aceptable ni como procedimiento subsidiario para la aplicación del impuesto principal.

La polivalencia de las versiones en renta maneja una posibilidad en el impuesto para determinar su base, mientras que el anticipo nace un tanto heterodoxo por considerar distinta materia gravable en la forma de emplear los métodos de cálculo, siendo este último el elemento que fija la naturaleza de la figura imponible, comprobando una desarticulación evidente.

Esta falta de conformidad entre las dos bases no puede ser justificada por la existencia de necesidades tributarias como la recaudación basada en el principio de eficiencia recaudatoria. La base imponible como parte legítima del objeto imponible debe estar obligada al estricto cumplimiento del principio de capacidad contributiva. Calvo Ortega (2006, 193-194), en ese sentido, advierte de la base liquidable que:

Este concepto no es esencialmente diferente al de base imponible. Si este mide la capacidad económica del contribuyente, la base liquidable debe hacerlo con mayor fidelidad si está correctamente justificada dentro de una norma tributaria [en definitiva, dentro de un tributo]. En resumen, debe ajustarse al principio de capacidad económica y a la progresividad como técnica instrumental del mismo, cuando tal progresividad sea exigida por la ley correspondiente.

Concluyendo este apartado, se debe indicar que las bases vía afectación patrimonial deberían tener tarifas fijas proporcionales al avalúo, no así la renta que debe ser progresiva. Lo ideal para gravar patrimonio mediante el impuesto a la renta es considerar para su afectación su potencialidad de dar renta y ahí cuantificar su afectación progresivamente. Es nuestro criterio in- 
dicar que el anticipo puede coexistir con una naturaleza mixta siempre y cuando sea coherente con tipos de tarifas congruentes con el impuesto que va a complementar.

\section{Metodología}

La metodología de investigación es cualitativa, de carácter documental bibliográfico, y el tipo de evidencia es, entre otras, fuentes normativas y fuentes documentales. Para el acopio y procesamiento de la información, los lugares sociales visitados fueron bibliotecas de la ciudad, bibliotecas virtuales, archivo de la Corte Constitucional del Ecuador, del Tribunal Distrital de lo Fiscal, de la Dirección Nacional del Servicio de Rentas Internas y Asamblea Nacional, centros de Estudios Fiscales.

El procesamiento de la evidencia se realizó mediante el enfoque cualitativo, que permitió una comprensión del objeto de estudio, con una aproximación de la realidad de una forma dinámica; la utilización del método sistemático ayudó a atender las evidentes contradicciones normativas; conforme el método exegético empleado, el uso de las herramientas oportunas permitió interpretar literalmente las normas que regulan el anticipo y aportar a una concatenación normativa y lógica de lo analizado. Mediante el método dogmático, se utilizó varias teorías que han tenido aceptación en cuanto a los presupuestos planteados.

\section{El anticipo: un impuesto encubierto, confusión de objetos imponibles}

Una de las cuestiones más conflictivas que se ha suscitado en torno a la naturaleza del anticipo es la de si su creación atiende a la constitucionalidad exigida como ingreso anticipado al Estado por configurarse con un objeto imponible de tipo incierto.

Esta dudosa regulación del anticipo está básicamente relacionada con la configuración del hecho generador (presupuesto o hipótesis) y la conforma- 
ción de los diferentes elementos que lo configuran. Contextualizando esta problemática se asume que, aun cuando el anticipo es legalmente exigible, su verdadero hecho generador es el uso de patrimonio para percibir rentas, no siendo análogo con el hecho generador del impuesto que complementa, significando en la práctica otro impuesto.

Lo que corresponde, por ahora, es abordar la forma en que se han involucrado distintas materias imponibles en las bases de cálculo entre el impuesto y su figura accesoria. En ese sentido, es necesario considerar las nociones del hecho generador y el objeto imponible. La doctrina ha determinado que: "El hecho imponible legal es una hipótesis delimitada por la ley que convoca a los supuestos [fácticos] que en la realidad puedan darse. Y como tal hipótesis legal define o delimita los supuestos de hecho con arreglo a actos o negocios o según categorías o conceptos económicos" (Albiñana García 1992, 76, énfasis añadido).

De manera que se entiende que el hecho imponible es siempre jurídico, y, como dice Ferreiro Lapatza $(2001,51)$ :

Riqueza gravada, objeto del tributo, solo es aquella parte de la riqueza acotada por las normas que delimitan el hecho imponible de cada tributo en tanto aparezca en las circunstancias descritas por estas normas. El objeto del tributo es así un concepto jurídico, una realidad jurídica.

Resulta evidente que, si el hecho generador es la expresión de una realidad tanto jurídica como económica, la ley debe precisar su cometimiento en tanto las circunstancias se ajusten al objeto principal del gravamen que, según Lejeune Valcarcel $(1989,190)$, debe estar "conectado a la exteriorización de una capacidad contributiva, conexión que normalmente se realiza a través de la definición del elemento material del hecho imponible".

La calificación de los hechos imponibles tiene en realidad una conexión determinante con el objeto imponible; por ello operativamente se considera el objeto imponible como un elemento esencial al construir un impuesto. Así lo ha señalado el autor Albiñana García $(1992,76)$ al explicar que: "El objeto imponible es la definición legal de la capacidad económica a gravar, y de aquí que deba estar presente en su ley reguladora si la capacidad económica, como parece obvio, es nervio y aliento del impuesto justo". 
Debe indicarse que, para la configuración práctica del impuesto, concurrirán de todas formas el objeto y el hecho imponible en la medida de que el primero indique una existencia real de la materia imponible, y el supuesto de hecho sea el llamado por la ley para configurar su acción última.

Fernández (2004) indica que es indispensable que el hecho generador del impuesto a la renta esté previsto en la ley; además, sostiene que puede utilizarse distintos elementos para fijarlo, dependiendo de la naturaleza de las rentas objeto de gravamen.

En lo referente a los factores que debe cumplir el hecho imponible, Albiñana García $(1992,272)$ sostiene que es necesario considerar el período de imposición, el elemento espacial, el devengo del impuesto, además dice que: "Constituirá el hecho imponible [...] la obtención de renta por el sujeto pasivo. No obstante, algún factor o elementos más ha de existir para que el hecho imponible, cumpla su esencial función, cual es la de generar la correspondiente obligación por este impuesto". Cabe decir que el período de cumplimiento de una obligación condiciona la imposición de cualquier obtención de rendimientos de las explotaciones económicas o circunstancias dadas por la ley.

Esta situación en el orden jurídico no ha logrado una definición concreta del hecho generador del impuesto a la renta. Es así que el art. 1 de la LORTI recoge el objeto del impuesto y señala que lo es respecto a un impuesto a la renta global que obtengan las personas naturales, las sucesiones indivisas y las sociedades nacionales o extranjeras.

Es prudente advertir que la LORTI ha recogido con claridad el presupuesto de hecho del impuesto a la renta, además con una dedicación inconclusa ha establecido un presupuesto que no está elaborado exactamente como la teoría exige. La falta de descripción de algunos componentes para considerar su existencia en la vida económica y su realización en el mundo jurídico son algunos de los injustificados lineamientos que no hace la ley para delimitarlo. Visiblemente el hecho de este impuesto carece de incidencia, porque su estructura no es completamente clara, no está asistido oportunamente por una hipótesis, un mandato y la determinación de un incumplimiento.

Si es una forma abstracta la que el legislador intentó rescatar en el impuesto, tiene un contenido muy trivial para lograr un alcance más óptimo sobre sus consecuencias jurídicas. La configuración del hecho generador es 
muy compleja y la ley se queda corta, se debe tomar más precisión y desentrañar todas aquellas circunstancias como la existencia de bienes, la conexión con un sujeto, o con un negocio jurídico; así se logrará una interpretación y aplicación en conjunto mucho más clara.

Existen, como se puede apreciar, elementos distintos en los contenidos del hecho y objeto imponible del anticipo; en tal sentido, las diferencias como veremos comparativamente son sustanciales. La afectación en el impuesto es sobre rentas e ingresos de fuente ecuatoriana y obtenidos en el exterior provenientes del capital, del trabajo o de ambas fuentes, no sucede lo mismo en el anticipo ya que este grava patrimonio y activo considerados en su totalidad.

Para dar continuidad a este análisis, se recuerda, en razón de las aportaciones que hace Leicach $(2005,263)$, la concepción del anticipo y su relación con el hecho imponible:

Los anticipos son obligaciones tributarias autónomas de cumplimiento independiente, que tienen su propia individualidad y fecha de vencimiento. Su exigencia reposa en la razonable presunción de continuidad de la actividad que da lugar a los hechos imponibles y que se basan en una presunción de capacidad contributiva con relación al impuesto determinado en períodos anteriores.

En función de esta consideración, resulta que, en el régimen tributario ecuatoriano, la exigibilidad del anticipo efectivamente viene dada según la presunción de la continuidad de una actividad económica o independiente; en virtud del art. 41, núm. 2 de la LORTI, se ha establecido que personas naturales y sociedades deberán determinar en su declaración correspondiente al ejercicio económico anterior. Llegando a este punto, es pertinente revisar si el hecho que conforma la materia imponible del anticipo está articulado al impuesto principal. Collado Yurrita $(1995,1373)$ explica que:

Naturalmente, en la medida en que a lo largo del período impositivo han surgido, a cargo del contribuyente, unas obligaciones pecuniarias de anticipación del impuesto, cuando al final de aquel se haya realizado el hecho imponible, de este surgirá una obligación tributaria por la cantidad que falta para que el sujeto pasivo cumpla con el tributo, con su deber de realizar una atribución patrimonial a favor de la hacienda pública que se corresponda con su capacidad económica. 
En efecto, el proceso de cálculo del anticipo ha vinculado, según disposición legal, la configuración del hecho imponible a partir de la tenencia de patrimonio y activos, considerados en su totalidad. Cabe decir que el hecho imponible debe ser distinguido como característico de la legitimidad de su abstracción: "el hecho imponible no solo ha actuado como presupuesto generador de la legitimidad constitucional de los ingresos a título de tributo, sino también como presupuesto generador de ingresos a título de tributo, sino también como presupuesto generador de obligaciones de entregar sumas de dinero" (Lejeune Valcarcel 1983, 173).

Como resultado de las circunstancias erróneas que considera la LORTI, al configurarlo, se afirma que se está instituyendo el hecho imponible de otro impuesto respecto del patrimonio; en esa línea se debe aclarar que el impuesto al patrimonio considera como, hecho según Albiñana García (1992, 337), "la titularidad por el sujeto pasivo en el momento del devengo, del patrimonio neto". Aquí el anticipo, en lugar de gravar al patrimonio neto como lo describe el autor, grava el total, siendo un elemento con características aún más confiscatorias, por no considerar la deducción de los gravámenes y deudas que lo estén afectando.

Debido a esto, la situación actual del anticipo es controversial frente a las teorías y principios que sostienen la progresividad y equidad del régimen tributario. Las circunstancias en el régimen se materializan a través de la equidad cuando el objetivo de la recaudación respeta la derivación de la justicia tributaria. La tributación tiene que reparar las diferencias de las riquezas que existen en una sociedad, asignando criterios de progresividad.

No se trata de un sistema de anticipación complementario, sino de otro impuesto en sentido estricto. Porque no corresponde a un pago anticipado que grava correctamente la renta potencial que procede del patrimonio productivo de un sujeto, sino de la afectación directa y errónea al patrimonio y activo total. En esa línea se ha expresado Pérez de Ayala (1978) cuando menciona que técnicamente se delimita el patrimonio según la materia o la fuente de afectación para calificar si no estamos ante un impuesto patrimonial complementario de la imposición sobre la renta, sino ante un impuesto confiscatorio o leva de capitales que bastará comprobar que la fuente con cargo a la cual se paga a aquel que es el propio patrimonio. 
Es evidente, entonces, que los activos totales que están considerados como materia imponible del anticipo no son técnicamente los mejores indicadores para reflejar una articulada imposición complementaria. Se diría pues que aquel compendio considerado por el art. 41, núm. 2, lit. b) de la Ley Sobre el Pago del Anticipo del Impuesto a la Renta supone la novedad de gravar activos totales que no están efectivizados en ganancias periódicas, ni tampoco en ganancias de capital; de ahí que no son activos que han generado renta y surgen razones para llamar al anticipo impuesto encubierto.

Con lo expuesto, se puede decir que los objetos y hechos imponibles distan mucho de ser semejantes y complementarios, de esta forma es inadmisible aceptar tal confusión. En ese sentido, es oportuno completar esta parte, con la exposición de algunas teorías relacionadas con la correcta complementación y la afectación de patrimonio y activos en renta en casos extraordinarios.

La determinación técnica es uno de los problemas que presenta el anticipo y deberán considerarse las contrariedades con los distintos principios en aras de evitar dificultades a las empresas como la descapitalización. Fijar este tipo de diferencias sustanciales evidencia que materias como el patrimonio y los activos deberían estar gravados por un impuesto patrimonial y no en el de renta.

En efecto, la ley puede estar instituyendo otro impuesto con el anticipo que, para efectos conceptuales, es un desconcierto con el régimen por suponer la entrega de una cantidad de dinero a concepto de una variedad de materias imponibles exigibles legalmente a título del impuesto de renta.

En fin, la operatividad en el cálculo del anticipo se desarticula totalmente del objeto imponible principal del impuesto a la renta que viene determinado con sus elementos según las teorías y técnicas tradicionales del tributo. 


\section{Problemas de doble imposición interna}

Todo lo dicho hasta ahora explica por qué se ha creado, mediante el anticipo, un nuevo impuesto ingeniosamente oculto con otro nombre. De acuerdo con la confusión de objetos imponibles, es un verdadero tributo distinto al de renta; de todo esto se desprenden varias dificultades, y una de ellas corresponde a que la materia imponible ya está afectada en otros impuestos. Resulta oportuno para este análisis recurrir a algunas teorías acerca de la doble imposición y sus más elementales conceptos básicos.

Es preciso resaltar inicialmente el criterio de Montaño Galarza (2006), quien realiza una precisión al decir que la doble imposición, como un fenómeno de naturaleza fiscal, puede tener varias connotaciones y manifestaciones, según se trate de su presencia con rasgos económicos o jurídicos, de derecho interno o internacional. Cabe agregar que el debate doctrinal sobre doble imposición se ha dedicado más a abordar el campo internacional, y este estudio de la imposición simultánea en el ámbito nacional resulta ser muy limitado.

Según lo que tradicionalmente defiende la doctrina como doble imposición internacional, Calderón Carrero (2010) sostiene que los elementos indispensables para poder apreciar la concurrencia de doble imposición internacional en sentido estricto vienen dados por la identidad de sujeto pasivo, de objeto imponible, de título impositivo y temporal, sumados a la diversidad de sujetos activos en las relaciones jurídico-tributarias.

A partir de estos elementos se puede identificar la existencia o no del elemento racionalizador en los factores de imposición interna. Como hemos visto la deficiencia técnica en la estructuración del anticipo compromete las condiciones en las que el régimen se subyace heterogéneo y presenta características imponibles que difícilmente son conexas entre los impuestos. Además, López Martínez (2000, 440) señala que:

El fenómeno de la doble o pluriimposición se produce cuando, sobre una misma manifestación de riqueza, inciden varias figuras tributarias, con independencia que estas vengan impuestas por el mismo ente con poder normativo en materia tributaria, por entes pertenecientes a distintos Estados, o por diversos entes con poder tributario dentro de un mismo Estado. 
A propósito de la convivencia de gravámenes sobre la misma materia imponible y sobre el mismo sujeto en un período determinado, ha resultado como aquella situación que reprime a los contribuyentes en una grave afectación de sus derechos, de garantías de un régimen congruente ausente de legitimidad y exigibilidad de justas cargas tributarias.

En ese orden de ideas, cabe distinguir la apreciación de López Martínez (2000) cuando indica que la doble imposición será, en consecuencia, aquel fenómeno a través del cual dos o más figuras tributarias, bien abierta, bien encubiertamente, recaigan sobre un mismo objeto imponible. Significa, entonces, que el legislador desarticula diferentes hechos de diversos tributos, instituyendo la duplicidad del aspecto material del tributo entre impuestos y figuras impositivas.

Los supuestos de doble imposición en el terreno nacional vienen dados por la habilitación legal del accionar de los sujetos activos, la regulación que establece el legislador y los gobiernos autónomos descentralizados cuando crean tributos y, obligatoriamente, atribuyen a diversos entes las facultades impositivas para administrarlos. Por lo tanto, la concurrencia de la facultad de exigir un tributo de una y otra administración con similares elementos impositivos que conformarán el fenómeno de la doble imposición interna.

Además, otro elemento es la identidad subjetiva para configurar la doble imposición. En ese sentido, Calderón Carrero (2010, 327), al considerar el método de imputación sobre un contribuyente, sostiene que:

Para dilucidar la apreciación de este requisito no se trata tanto de fijarse en quién realiza las prestaciones tributarias materiales y formales [...] de los impuestos, sino de analizar si las leyes fiscales que regulan los impuestos yuxtapuestos imponen sobre la misma persona la carga tributaria del hecho imponible.

Para lograr una identidad absoluta la doble imposición interna deberá tomar en cuenta la materia sustancial del tributo, que en todo caso deberá tener una naturaleza idéntica. López Martínez $(2000,440)$ indica que:

En consecuencia, no basta con el análisis aislado del hecho generador de los tributos, sino que el método para obtener alguna conclusión debe consistir en analizar la congruencia o incongruencia entre el presupuesto de hecho definido en la ley para cada tributo, y la base imponible definida en la ley para cada hecho imponible. 
Ya se había señalado que la confusión de los objetos imponibles en la base de cálculo del anticipo presenta varios elementos incongruentes con el propio impuesto a la renta; ahora, este objeto material de la base resulta controversial porque su naturaleza coincide con los elementos materiales considerados en algunos impuestos locales.

Para proseguir el análisis, se describe la situación actual en el régimen ecuatoriano, para lo cual se revisa la concurrencia total o parcial de tales elementos dispuestos en las órbitas subjetivas, objetiva o espacial del hecho imponible del tributo aplicado a la renta o al patrimonio, y se define si el fenómeno causa un doble gravamen jurídico y un doble gravamen económico. Los rasgos económicos o jurídicos que presenta el anticipo a la renta difieren del observado en otras figuras impositivas que coinciden en algunos elementos constitutivos del tributo (Montaño Galarza 2006).

Ahora bien, la doble imposición jurídica ha sido definida por la Organización para la Cooperación y el Desarrollo Económico (OCDE) como: "El resultado de la aplicación de impuestos similares en dos o más Estados a un mismo contribuyente, respecto a la misma materia imponible y por el mismo período de tiempo" (OCDE 1997, 7). Nótese, entonces, que este fenómeno presenta la concurrencia de potestades tributarias, y que exige para su configuración el elemento de presentarse con identidad subjetiva, característica que distingue a esta doble imposición jurídica de la económica.

En el anticipo se dan las notas típicas de la doble imposición jurídica, esto en razón de que presenta problemas de doble imposición respecto de algunos impuestos locales. La presencia de elementos como la imposición concurrente de figuras impositivas sobre un mismo sujeto con dos sujetos activos que reclaman la imposición de una misma materia imponible, en el mismo período, son elementos determinantes para afirmar que, más que una doble imposición económica, de la relación entre el anticipo con otros impuestos locales, existe doble imposición jurídica interna.

\section{Impuesto predial y anticipo}

En el anticipo pueden ser sujetos pasivos las personas naturales, sucesiones indivisas y sociedades; estos contribuyentes están obligados al pago del 
impuesto predial cuando son propietarios de predios ubicados dentro de los límites de las zonas urbanas y fuera de ellas. La doble imposición juega en este caso una identidad subjetiva.

Respecto de la temporalidad, el impuesto grava durante el curso del respectivo año, con base en el catastro del año anterior; de igual forma el período gravado en el anticipo corresponde a un pago con cargo al ejercicio fiscal corriente, en relación al ejercicio económico anterior; por lo tanto, tienen identidad en los períodos impositivos.

Si se revisan ahora las similitudes entre los objetos imponibles en el régimen ecuatoriano, el objeto del gravamen del predial urbano consiste en la propiedad del inmueble a cargo de su titular en la zona urbana. Para el impuesto predial rural, el objeto del impuesto es la titularidad y posesión de bienes inmuebles situados fuera de los límites del área urbana, con afectación al valor que cada zona tenga más lo considerado por valor de edificaciones y tierra.

Conviene añadir en este punto la apreciación del objeto imponible del impuesto predial que menciona Acevedo (2008); el impuesto predial unificado toma por objeto imponible una de las manifestaciones clásicas de capacidad contributiva: el patrimonio -expresión jurídica de la riqueza-, entendiendo como la universalidad jurídica que agrupa bienes y derechos (reales y personales) susceptibles de valoración pecuniaria.

El tipo de patrimonio objeto de este impuesto municipal es, según López Espadafor (2000, 474): "Constituido por la titularidad de riqueza inmobiliaria [...] debemos decir que tal objeto material aparece constituido por el patrimonio inmobiliario".

Visto que el objeto material del impuesto está gravando el patrimonio inmobiliario, resulta claro que esa situación se superpone al anticipo del impuesto a la renta que grava el patrimonio total, siendo el patrimonio inmobiliario parte de esa totalidad que afecta el anticipo. 


\section{Impuesto sobre los vehículos y el anticipo}

En el caso del impuesto sobre los vehículos, el sujeto activo corresponde a la municipalidad o al distrito metropolitano, y es distinto al sujeto activo del anticipo que en su caso corresponde al Estado (administrado por el Servicio de Rentas Internas). Por otro lado, se relacionan con los mismos sujetos pasivos, por lo cual toda persona natural o sociedad propietaria de un vehículo debe tanto el anticipo como el impuesto sobre los vehículos. El período del anticipo es sobre el ejercicio fiscal corriente; de la misma manera, el impuesto corresponde a un pago anual.

Ahora bien, si se analiza la comparación de las reglas de determinación de las bases imponibles, uno y otro objeto coinciden; el impuesto sobre los vehículos fija una tarifa para cada avalúo y, en ese contexto, el patrimonio total que grave el anticipo considerará como un indicador de la base de su cálculo al avalúo de los vehículos. Como resultado, el contribuyente está frente a la afectación de la misma materia imponible por dos figuras distintas.

Además, es conveniente recalcar que este impuesto sobre los vehículos presenta una situación bastante controversial porque, además de tener doble imposición interna con el anticipo, muestra varios inconvenientes de doble imposición con el impuesto anual sobre la propiedad de los vehículos motorizados por afectar a vehículos de transporte terrestre de personas o carga, particular o público, cuyo sujeto activo es el Estado administrado por el Servicio de Rentas Internas; de allí que para Montaño y Mogrovejo (2014, 188-189):

Supone un desequilibrio del sistema tributario imperante en el Ecuador, porque como se ha demostrado, resulta que coexisten dos impuestos de la misma naturaleza en cuanto al hecho generador, sujetos pasivos y período de causación, con distintos sujetos activos [...] por la vigencia de dos cargas impositivas que gravan una misma manifestación de riqueza, desdice la racionalización sistemática impositiva que debe primar en el país.

En esa línea resulta cuestionable la forma en la que se dispone el gravamen de estos tributos y el anticipo del impuesto a la renta. En virtud de esta situación es necesario que se logre una articulación de los objetos imponibles establecidos paralelamente con algunos principios que limiten aquellas 
potestades impositivas, con el fin de coordinar las posibles precisiones de afectación y lograr un sistema impositivo más dinámico y moderno. ${ }^{1}$

\section{Impuesto a la patente municipal y el anticipo}

Resulta que los sujetos pasivos del anticipo y del impuesto podrían ser los mismos, por lo cual todo contribuyente que ejerza permanentemente actividades comerciales, industriales, financieras, inmobiliarias y profesionales y que se ubique dentro de esta calificación, que hace la ley para establecer la obligación de adquirir una patente, también estarían obligados a pagar el anticipo.

En relación con el período impositivo, tanto en el anticipo como en la patente la exigibilidad para el pago es anual. Esta identidad temporal parte de la precisión muy acertada que realiza Montaño Galarza $(2006,117)$ al mencionar: "hace alusión a la realización del hecho imponible en un mismo período, o, lo que es lo mismo, a la yuxtaposición de soberanías fiscales esta-

1. Un caso aún más controversial sobre la doble imposición interna es lo que actualmente pasa en Ecuador con el tema del impuesto a la plusvalía sobre la ganancia extraordinaria de bienes inmuebles. Es un capítulo especial de los últimos proyectos de reforma tributaria en el ámbito territorial. Este es un tributo inmobiliario, utilizado desde el siglo XIX en Alemania, y presenta una estructura jurídica establecida como recurso de financiación y gestión de municipios y distritos. Ahora, como fundamento en el trámite legislativo que se discute en el país, de esta propuesta resulta que el Estado central también es beneficiario. Además podemos identificar el fenómeno de doble imposición interna cuando grava la renta expresada en la ganancia extraordinaria en la transferencia de dominio de un bien inmueble; si esto es una utilidad por razones justificadas en la acción urbanística de entidades del gobierno, con una tarifa muy alta con rasgos confiscatorios, se podría decir que viene a representar una carga excesiva porque ya el impuesto a la renta y su anticipo consideran para su configuración los ingresos de venta de bienes inmuebles. Y, aunque la forma del cálculo de la plusvalía extraordinaria fije estándares para una base imponible totalmente depurada, nos parece que la ganancia extraordinaria es una renta que ya se encuentra gravada por otro impuesto. En resumen, este proyecto no es un marco legal fácil de implementar; una propuesta como esta, para que sea sostenible y equitativa, debe observar estrictamente los límites de coordinación en el régimen, tomando en cuenta los impuestos existentes sobre ganancias de capital y sobre la propiedad inmobiliaria. Asimismo, con el debate que se ha suscitado, el proyecto tiene elementos muy dispersos, que provocan una mala dirección de la naturaleza del impuesto. Cuando se insiste en lograr fines no acordes a los desarrollados en las teorías del tributo, se pierde toda perspectiva de justicia. 
tales que apuntan a gravar la capacidad económica de un sujeto obligado que tienen o que obtiene en un mismo momento".

Ahora bien, en relación con la materia imponible del impuesto a la patente y el anticipo resultan ser estrictamente similares; esto porque la imposición sobre la patente recae en función del patrimonio de los sujetos pasivos de este impuesto dentro del cantón, es decir, es el mismo objeto sustancial del anticipo, cuando este último grava el patrimonio total considerado para efectos del cálculo en la base. Siendo la esencial coincidencia que ambas figuras gravan directamente un elemento patrimonial, corresponde a una prueba más para considerar al anticipo como un impuesto encubierto.

\section{Impuesto al 1,5 por mil de los activos y el anticipo}

En lo que se refiere a los contribuyentes en su mayoría coinciden en el anticipo y en el impuesto, por tanto, quienes se dediquen al ejercicio permanente de actividades económicas y que estén obligados a llevar contabilidad deberán pagar el impuesto y también el anticipo. A propósito del período impositivo, este impuesto considera el pago a cada año calendario al igual que el anticipo.

Previamente se ha distinguido que la base de cálculo del anticipo supone la afectación de los activos totales, en ese sentido en el impuesto, y como su nombre lo indica, la materia imponible es el activo total del año calendario anterior. Aunque la normativa local disponga la posibilidad de realizar la deducción de las obligaciones de hasta un año plazo y los pasivos contingentes, esa consideración no desvía la reflexión de que es el mismo objeto imponible y que resultado de esta determinación se configura una doble imposición interna.

\section{Impuesto de alcabala y el anticipo}

En este impuesto existe la concurrencia de dos gravámenes sobre el mismo sujeto pasivo, por tanto, se explica que las personas naturales, sucesiones 
indivisas o sociedades obligadas al pago del anticipo también pueden ser sujetos pasivos del impuesto de alcabala cuando tengan la calidad de contratantes y reciban beneficio de un contrato.

Cabe indicar que, a diferencia de los demás impuestos locales, el elemento de la temporalidad no coincide en estas figuras. El impuesto, en el hecho imponible, se efectiviza cuando se realizan actos jurídicos que contengan el traspaso de dominio de bienes inmuebles, es decir, el período de realización es incierto, al contrario del período anual del anticipo, y no descarta la posibilidad de que coincidan en el período impositivo.

Resulta interesante la manera en la cual la materia imponible del impuesto coincide con la del anticipo. Se ha constituido como base del impuesto al indicador del valor contractual, y si este fuere inferior al avalúo de la propiedad que conste en el catastro, regirá este último, es decir, que la base del impuesto está vinculada a gravar el valor de la propiedad, afectando el patrimonio por ambas figuras impositivas, una en razón del tributo local y la otra en razón del impuesto a la renta. Siendo así, es muy precisa la reflexión que hace Montaño Galarza al explicar que el fenómeno por el cual ciertas materias impositivas se gravan proporcionalmente con mayor intensidad que otras, como causa de fallos en el sistema tributario (2006).

Por las descripciones ya anotadas, se puede identificar que existe una doble imposición interna producto de un grave error en la dinámica impositiva del régimen; hay identidad subjetiva, temporal y sobre todo material y esto representa un problema irreparable de índole económico para los contribuyentes, ya que hay más cargas para los sujetos cuando no se efectiviza la política de racionalización del régimen tributario.

La doble imposición interna es un tema muy complejo, y es necesario que los distintos órganos territoriales aborden la problemática atendiendo a los distintos principios materiales con el fin de controlar adecuadamente que los niveles de imposición se regulen articuladamente para evitar cargas fiscales excesivas. 


\section{Hallazgos relevantes}

Sobre la base de las consideraciones anteriores se ha intentado probar que un mismo objeto imponible está gravado por distintas figuras impositivas, coincidentes con el anticipo del impuesto a la renta.

Es necesario que la estructura de la tributación local y nacional coexista coordinadamente. Como se ha recalcado, los grandes impuestos, como el de renta a escala estatal, dejan un estrecho margen a la imposición municipal, por lo cual se cuestiona principalmente la creación de figuras heterodoxas como el anticipo, que están afectando directamente el patrimonio, cuando hay impuestos locales que tradicionalmente ya lo gravan.

La estructura técnica de los tributos locales responde a una finalidad concreta de orden territorial, para la renovación urbana, la conservación del patrimonio cultural y la necesidad de garantizar un ambiente sano a los contribuyentes locales. Esta es la razón por la cual se han creado instrumentos fiscales en el ámbito local para gravar el patrimonio. Cabe plantearse la pregunta ¿cuál es el fundamento que tiene el anticipo del impuesto a la renta para gravar patrimonio? A nuestro juicio, la formulación normativa en el anticipo no lleva explicita la finalidad que justifique su afectación.

La racionalidad interna de cada figura tributaria tiene que presentar una capacidad especial para combinarse armónicamente a los demás impuestos que integran el régimen. En primer término, se ha considerado que los hechos generadores en todos estos impuestos locales se configuran de manera particular: al analizar la riqueza imponible que están afectando, se encuentra que es la misma que la del anticipo.

Como se analizó en la delimitación del objeto imponible, ambas dimensiones normativas coinciden cuando gravan el patrimonio, circunstancia que produce el fenómeno de la doble imposición interna por coincidir en uno y otro sobre el mismo objeto imponible.

De las comparaciones antes explicadas, nos interesa dejar claro que la doble imposición sin duda incide sobre los principios de justicia tributaria. La operatividad actual del fenómeno ha permitido que estos conflictos perjudiquen a contribuyentes en términos de desigualdad, capacidad económica y confiscatoriedad por la proyección de varias figuras que gravan una misma riqueza. 
El efecto multiplicador del fenómeno en la tributación seguirá afectando a los contribuyentes si no se establece la idoneidad del hecho y el objeto imponible en varios impuestos. Es imperioso que el legislador seleccione los índices directos de la capacidad para soportar la carga tributaria, como lograr la articulación del resto de elementos estructurales de los tributos, para que no graven el mismo objeto.

\section{Afectación de principios de rango constitucional y legal}

La afectación de principios tributarios como el de seguridad, capacidad contributiva e igualdad tiene que ver fundamentalmente con la errada determinación de los elementos técnicos del anticipo. Las reformas tributarias han desencadenado una grave incertidumbre e inseguridad jurídica respecto de la figura. La disciplina que regula el anticipo atenta contra la disposición constitucional de un sistema equitativo y justo. Naturalmente la necesidad del Estado de resolver su financiamiento con sistemas anticipados de cobro, compromete el derecho de propiedad de los contribuyentes, el alcance confiscatorio de la forma de imposición del anticipo representa una afectación importante en el giro de los negocios y planificación. El recargo de asumir bajo condiciones desalentadoras al ahorro, a la inversión y a la igualdad, es un obstáculo que proyecta a la normativa del anticipo como una figura incompleta, que está trasgrediendo las más elementales garantías en el régimen.

\section{Vías de solución a la problemática analizada}

Se ha dejado para el final de este trabajo algunos aportes personales con el objetivo de ampliar el tema abordado. De los planteamientos se ha encontrado un punto intermedio en la problemática analizada, en que el anticipo pueda coexistir con el impuesto a la renta, siempre que se realice una reforma sustancial en su base de cálculo y se distinga de una mejor manera a las per- 
sonas obligadas a su pago. Para dar continuidad a este apartado se exponen algunas sugerencias que recapitulan todo lo explicado anteriormente.

Como ya se mencionó, el anticipo merece una reforma en la que se tome como vía la compatibilidad que debe llevar con el impuesto a la renta: para ello, el anticipo debe limitar su objeto imponible únicamente a la renta. El legislador deberá describir categóricamente cuáles son los rendimientos que afecta la base de cálculo del anticipo. Paralelamente a este cambio se debería manejar un procedimiento distinto de cuantificación, pues lo mejor es que opere con una imposición por tramos según los ingresos gravables con variedad en la tarifa del anticipo, de tal forma que se adecue al manejo progresivo que tiene el impuesto.

Los regímenes tributarios en Ecuador y España tienen sin duda una línea ortodoxa similar. Por ello, en materia de soluciones, se intenta tomar como guía el sistema de pagos a cuenta que maneja este país. Debido a que se ha desarrollado de forma armónica, orientado por una oportuna diligencia demostrando que su funcionamiento ha sido exitoso y que ha operado en los últimos años con mínimas dificultades.

Ecuador podría aplicar algo similar al modelo español, en este país los pagos a cuenta están descritos por la Ley 35/2006 (ES 2006), normativa que ha presentado las características esenciales, como la definición, transmisión y obligaciones formales; oportunamente la ley ha descrito el detalle de los rendimientos sujetos al pago, ha complementado su aplicación mediante la aplicación separada de los pagos a cuenta de personas físicas y personas naturales.

Además, el régimen tributario en Uruguay establece un sistema de pagos a cuenta similar al español. La Ley del Impuesto a la Renta de actividades (UY 2007) económicas señala que: "A los efectos de determinar el monto de los pagos a cuenta se deberá obtener la relación entre el monto del impuesto y las ventas, servicios y otras rentas brutas que originen rentas gravadas en cada ejercicio" (Ley 150/007, art. 165).

También se puede recomendar, como vía de solución, la modificación en la carta constitucional de salvaguardar la unidad y coherencia en el régimen; para ello se deberá desde disposición constitucional imponer la prohibición de fenómenos como la doble imposición interna. Esta solución puede ser la más difícil de implementar. Sin duda, es indispensable que casos excepcio- 
nales como el anticipo se vayan eliminando por estar tratando en él un impuesto encubierto, haciendo con los demás tributos locales un sistema muy gravoso para el contribuyente.

En atención a este argumento, el mandato constitucional de la Constitución guatemalteca tiene una tendencia para legitimar su regulación fiscal en aras de eliminar las situaciones de doble imposición. Ha desarrollado su concepto desde la ley suprema en este país al promulgar:

Hay doble o múltiple tributación, cuando un mismo hecho generador atribuible al mismo sujeto pasivo, es gravado dos o más veces, por uno o más sujetos con poder tributario y por el mismo evento o período de imposición. Los casos de doble o múltiple tributación al ser promulgada la presente Constitución, deberán eliminarse progresivamente, para no dañar al fisco (Constitución Política de la República de Guatemala 1985, art. 243).

La organización jurídica en el Estado de Guatemala considera, como una idea fundamental y factor cambiante, establecer el principio de la prohibición de la doble imposición interna; en este país, este principio se constituye como un límite para el poder legislativo; la observancia a la prohibición del establecimiento de doble o múltiple tributación interna constituye un parámetro a ser respetado por el Congreso de la República, procediendo a decretar impuestos ordinarios y extraordinarios, arbitrios y contribuciones especiales, así como al determinar las bases de su recaudación (Guzmán 2012).

Para evitar cualquier hecho referente a doble imposición interna, se debe establecer el principio de coordinación en el régimen tributario, que además tendría que hacer un reordenamiento claro del reparto del poder impositivo de todas las instituciones territoriales. En atención a la equidad y descentralización, la carga fiscal podrá sostenerse en aras de atender autonomía y suficiencia de los fondos para restablecer un orden adecuado que no afecte a los ciudadanos. Un ejemplo de esta recomendación se encuentra en la Ley Fundamental para la República Federal de Alemania, que describe detalladamente, desde esta norma constitucional, cuál es el reparto y los alcances de la participación de entes locales y nacionales de cada tipo de tributo. La redacción de este artículo en la Constitución alemana distingue al originario poder tributario del Estado de las demás potestades, de las administraciones territoriales; no es la intención desconocer sino orientar de manera detallada ese reparto desde la norma constitucional. 
Por otra parte, una consideración más para el buen manejo del anticipo será que la base de la estructura de los tributos se dicte en razón del principio de capacidad contributiva, que presupone el vértice de la justicia y equidad en el régimen.

Todo presupuesto impositivo debe considerar determinadas circunstancias y categorías que se ajusten a un trato igual y justo según su capacidad contributiva. Este principio está previsto en las constituciones de Guatemala y Honduras, y ha sido muchas veces empleado en la Corte Constitucional rescatando que su fundamento es la intención de eliminar impuestos que no consideren la situación personal del sujeto pasivo, la aptitud efectiva del mismo y la base imponible del tributo.

Con el fin de evitar figuras impositivas que tengan fines ocultos y distintos al de su creación y que su aplicación afecte gravemente a los contribuyentes, la Constitución de la República del Ecuador deberá incluir, dentro del contexto que ha establecido de la prohibición de todo acto de confiscación, la disposición que garantice un régimen tributario adecuado al criterio de no confiscación, con la finalidad de suprimir los casos que por vía indirecta estén anulando esa garantía constitucional. Para ejemplificar y reforzar esta vía, se puede citar que, conforme los derechos y deberes establecidos en la Constitución de España, en su art. 31 se garantiza un sistema tributario justo que en ningún caso tendrá alcance confiscatorio.

Este principio fue recogido por la norma constitucional española porque le permite valorar si la afectación de los bienes del contribuyente, mediante el sistema tributario, es legítima o no; en todo caso, se ha implementado este principio para fijar un límite a partir del cual se pueda entender que se está desnaturalizando el tributo, usando el mismo como un medio sancionador, así como se fija un límite a la acción redistributiva del Estado.

Por último, se presentan algunas ideas que son innovadoras en la materia y tienen como fin establecer que las normas de aplicación de la ley fiscal protejan eficazmente la participación de los contribuyentes en términos de igualdad de condiciones frente a las prerrogativas de la administración tributaria central.

Estas propuestas tienen que ver, por una parte, con el mecanismo de devolución del anticipo, y, por otra, con la implementación de la oportunidad 
de poder elegir la modalidad del pago del anticipo, presentándose con ello un mecanismo de incentivos.

El mecanismo de devolución vigente del anticipo debe volverse menos agresivo. La disposición actual en cuanto a la posible devolución cada trienio cuando, por caso fortuito o fuerza mayor, la actividad económica del sujeto pasivo se haya visto afectada gravemente, es muy estricta al mencionar que, en caso de no ser autorizado, su devolución se constituirá en pago definitivo del impuesto a la renta, sin derecho a crédito tributario posterior. Esta norma deberá reformularse en razón de las circunstancias personales, registros y especificaciones técnicas para valorar mencionada negativa.

El pago del anticipo resta sin duda liquidez en el capital de un contribuyente, por un determinado tiempo. Así, los pagos que haga deberán tener tal precisión que no induzcan a error en su cálculo.

Resultado de esos errores son los pagos realizados en exceso o pagados indebidamente. Parece lógico, por tanto, mencionar que el Estado es participe de ese traspié en el cálculo. En ese sentido, adviértase que el Estado, cuando deja de percibir sus tributos, tiene derecho a reclamar intereses; por ello se puede sostener que, como caso excepcional y dadas las circunstancias del sacrifico económico del contribuyente, la ley considere, en el mecanismo de devolución, el derecho del contribuyente de exigir sus intereses en razón de su afectación.

Una línea doctrinal semejante a este planteamiento es abordada por Lejeune Valcarcel $(1983,110)$ al decir:

La sola devolución del eventual exceso no deja indemne del sacrificio económico soportado por quien ha tenido que realizar un ingreso anticipado que luego resulta ser excesivo. Tal sacrificio únicamente puede ser, en su opinión, compensado si además de devolverse el exceso de ingreso se abonan los intereses [...] amortiguando así los efectos económicos del empobrecimiento del contribuyente, no justificado desde el punto de vista del principio de la capacidad contributiva.

Una última consideración respecto de las vías de solución tiene relación con la modalidad del pago anticipado del impuesto. Se puede considerar una moderada salida establecer formas de cálculo que se ajusten a la situación real del contribuyente. Es pertinente considerar el establecimiento efectivo que ha hecho España en relación con el modo de pago: por un lado, se puede 
elegir que los cálculos sean con base al último impuesto pagado o la otra opción es la posibilidad de realizar el cálculo de acuerdo a los resultados reales del ejercicio actual que consiste en verificar en un cierre de fechas al mes a pagar del ejercicio corriente; complementando estas opciones, la administración tributaria en España separa el pago en tres fechas: abril, octubre y diciembre, ajustando los datos en casillas de registro.

Para una adecuada planificación de los contribuyentes se podría optar por el pago del anticipo como se da en España. Lo interesante de esta forma de pago es que se hace con cortes dentro del año y la persona paga de acuerdo a sus rentas reales. Este procedimiento estaría articulando la justa aplicación del anticipo, en el que se hace al contribuyente participe de su propia planificación económica, profesional o independiente. Por tanto, sería más correcto hablar de un mecanismo de pago que elige el contribuyente para mayor comodidad que una figura netamente recaudatoria.

\section{Conclusiones}

A manera de conclusión, el anticipo a la renta ha ganado mucho terreno en el principio de suficiencia recaudatoria. El problema central es que el Estado exige un pago anticipado encubriendo un impuesto distinto, por cuanto, al tener como objeto imponible a la totalidad del patrimonio y activos, se impone un gravamen de distinta naturaleza al de renta, y, en ese sentido, se plantea la necesidad de eliminar los vicios de cuantificación que considera la base y dejar de afectar al contribuyente indirectamente con figuras que no están investidas de legitimidad absoluta; el anticipo es una figura impositiva que encubre otro impuesto, con lo que se pierde toda perspectiva de encontrar coherencia en el tratamiento de la base de cálculo.

La disfuncionalidad entre el anticipo y otros impuestos locales subyace en problemas de doble imposición interna y las condiciones características de los elementos que conforman el anticipo comprometen la garantía de tener un régimen congruente. Para apartar todo tipo de doble imposición interna, se ha dejado planteada la necesidad de mejorar el reparto de potestades impositivas, vinculada a una efectiva claridad en la ley para controlar ade- 
cuadamente que los niveles de imposición se regulen articuladamente para evitar cargas fiscales excesivas.

\section{Referencias}

Acevedo Zapata, Sandra. 2008. "Impuesto predial”. En Julio R. Piza, coord., Régimen impositivo de las entidades territoriales en Colombia, 130-145. Bogotá: Universidad Externado de Colombia / Xpress Estudio Gráfico.

Albiñana García, César. 1992. Sistema tributario español y comparado. Madrid: Tecnos.

Calderón Carrero, José Manuel. 2010. "La doble imposición internacional y los métodos para su eliminación”. En Fernando Serrado Antón, dir., Fiscalidad internacional, 322-335. Madrid: Centro de Estudios Financieros.

Calvo Ortega, Rafael. 2006. "Cuantificación de la obligación tributaria”. En Rafael Calvo Ortega, edit., Curso de derecho financiero: derecho tributario, 183-197. Navarra: Aranzadi.

Collado Yurrita, Miguel Ángel. 1995. "Retenciones y otros pagos a cuenta". En Eugenio Simón Acosta, coord., Comentarios a la Ley del Impuesto sobre la Renta de las Personas Físicas y a la Ley del Impuesto sobre el Patrimonio, 1360-1375. Pamplona: Aranzadi.

Fernández, Luis Omar. 2004. "El impuesto a la renta". En Vicente O. Díaz, Política y economía tributaria, 1-25. Buenos Aires: Astrea.

Ferreiro Lapatza, José Juan. 2001. "Los elementos constitutivos de la obligación tributaria". En Andrea Amatucci, dir., Tratado de derecho tributario, 45-58. Bogotá: Temis.

Jarach, Dino. 1999. Finanzas públicas y derecho tributario. Buenos Aires: Abeledo Perrot.

Leicach, Jorge. 2005. “El pago”. En Mario Volman, dir., Régimen tributario, 260-273. Buenos Aires: Fondo Editorial de Derecho y Economía.

Lejeune Valcarcel, Ernesto. 1983. La anticipación de ingresos en el impuesto sobre la renta de las personas físicas. Madrid: Edersa.

López Espadafor, Carlos María. 2000. "La confluencia entre el impuesto sobre bienes inmuebles y la imposición estatal sobre el patrimonio". En José Sánchez, coord., Estudios sobre fiscalidad inmobiliaria y doble imposición interna, 465-480. Granada: Comares.

López Martínez, Juan. 2000. "La doble imposición interna en nuestro ordenamiento constitucional: un problema de reparto de poder tributario". En José Sánchez, coord., Estudios sobre fiscalidad inmobiliaria y doble imposición interna, 437-464. Granada: Comares.

Montaño Galarza, César. 2006. Manual de Derecho tributario internacional. Quito: Corporación Editora Nacional / Universidad Andina Simón Bolívar, Sede Ecuador.

---, y Juan Carlos Mogrovejo. 2014. Derecho tributario municipal ecuatoriano. Fundamentos y práctica. Quito: Universidad Andina Simón Bolívar, Sede Ecuador / Corporación Editora Nacional. 
Problemas y desafíos en torno al anticipo del impuesto a la renta

OCDE (Organización para la Cooperación y el Desarrollo Económicos). 1997. Modelo de convenio fiscal. París: Instituto de Estudios Fiscales.

Pérez de Ayala, José. 1978. Explicación de la técnica de los impuestos. Madrid: Adersa.

Schmölders, Günter. 1962. Teoría general del impuesto. Madrid: Editorial de Derecho Financiero.

\section{Normativa}

DEU. 2006. Ley Fundamental de la República Federal de Alemania. Boletín Oficial Federal III 100-1, 23 de mayo de 1949. Última revisión: 28 de agosto de 2006.

EC. 2004. Ley Orgánica de Régimen Tributario Interno. Registro Oficial 463, Suplemento, 17 de noviembre de 2004.

---. 2010. Código Orgánico de Organización Territorial, Autonomía y Desarrollo. Registro Oficial 303, Suplemento, 10 de octubre de 2010.

---. 2010. Reglamento a la Ley Orgánica de Régimen Tributario Interno. Registro Oficial 209, Suplemento, 8 de junio de 2010.

ESP. 2004. España. Ley 439/2007. Real Decreto 439/2007, 30 de marzo de 2007.

---. 2006. Ley 35/2006, Ley del Impuesto sobre la renta de las personas físicas y de modificación parcial de las leyes de los impuestos sobre sociedades, sobre la renta de no residentes y sobre el patrimonio. BOE 285, Ley 35/2006, 29 de noviembre de 2006.

GTM. 1985. Constitución Política de la República de Guatemala, 31 de mayo de 1985. Reformada por acuerdo legislativo 18-93, 17 de noviembre de 1993.

UY. 2007. Ley 150/007. Ley del Impuesto a la Renta de actividades económicas. Decreto 150/007, 26 de abril de 2007. 